\title{
Erosão hídrica pós-plantio em florestas de eucalipto na região centro-leste de Minas Gerais
}

\author{
Lislane Sousa Pires ${ }^{(1)}$, Marx Leandro Naves Silva ${ }^{(2)}$, Nilton Curi(2), Fernando Palha Leite ${ }^{(3)}$ \\ e Liziane de Figueiredo Brito ${ }^{(4)}$
}

\begin{abstract}
(1)Rua Júlio Malara, № 211, Bairro Cidade Jardim, CEP 14805-167 Araraquara, SP. E-mail: lislane@ufla.br (2)Universidade Federal de Lavras, Dep. de Ciência do Solo, Caixa Postal 37, CEP 37200-000 Lavras, MG. E-mail: marx@ufla.br, niltcuri@ufla.br (3)Cenibra S.A., Caixa Postal 100, Bairro Horto, CEP 35162-970 Ipatinga, MG. E-mail: fernando.leite@cenibra.com.br (4)Universidade Estadual Paulista, Fac. de Ciências Agropecuárias e Veterinárias, Rod. Carlos Tonani, Km 5, CEP 14870-000 Jaboticabal, SP. E-mail: liziane@fcav.unesp.br
\end{abstract}

Resumo - O objetivo deste trabalho foi avaliar as perdas de solo e água por erosão hídrica, em parcelas-padrão sob chuva natural, no período pós-plantio, em diferentes sistemas de manejo de florestas de eucalipto. O experimento foi instalado em Latossolo Vermelho-Amarelo, muito argiloso, relevo ondulado. As coletas de dados foram realizadas no período de outubro de 2002 a fevereiro de 2004, em eventos de chuva considerada erosiva. Os sistemas estudados foram: mata nativa; pastagem plantada; eucalipto plantado em nível; eucalipto plantado na direção do declive; eucalipto plantado na direção do declive com queima de restos culturais; e solo descoberto. Entre os sistemas florestais, o eucalipto em nível é o que mais se aproxima da mata nativa, em perdas de solo, indicando assim maior sustentabilidade desse sistema. Os maiores valores de perda de água são encontrados no sistema eucalipto plantado na direção do declive com queima de restos culturais, sugerindo que o fogo aumenta a repelência à água e diminui a taxa de infiltração de água no solo. Todos os sistemas de manejo do eucalipto estudados apresentaram perdas de solo inferiores ao limite de tolerância.

Termos para indexação: perdas de solo e água, essências florestais, Latossolo, manejo.

\section{Water erosion in post-planting eucalyptus forests at center-east region of Minas Gerais State, Brazil}

\begin{abstract}
The objective of this work was to evaluate soil and water losses by hydric erosion, in standard plots under natural rainfall, in different management systems of post-planting eucalyptus forests. The experiment was installed in an undulated relief, on a very clayey Typic Haplustox. The data collections were performed from October 2002 to February 2004, in rain events considered erosive. The studied systems were: native forest; planted pasture; cross slope direction eucalyptus; slop direction eucalyptus; slope direction eucalyptus with burning of crop residues, and bare soil. Among the forest systems, the cross slope direction eucalyptus is the one which is closer to the native forest in terms of soil losses, indicating the highest sustainability of the former in the water erosion context. The higher values of water losses, were found in the slope direction eucalyptus system with burning of crop residues, suggesting that the fire both increases repellence to water and diminishes water infiltration rates in soil. All the eucalyptus management systems presented soil losses below tolerance limit.
\end{abstract}

Index terms: soil and water losses, forest essences, Oxisol, management systems.

\section{Introdução}

A erosão hídrica é um processo complexo que se manifesta em intensidade variável, dependendo da interação dos fatores clima, solo, topografia, vegetação, uso da terra e práticas conservacionistas. Entre estes, a cobertura do solo é o fator isolado mais determinante na erosão hídrica (Foster, 1982), mas a rugosidade da superfície e as propriedades físicas na camada superficial e subsuperficial do solo (Allmaras et al., 1966; Cogo et al., 1984; Martins et al., 2002) também contribuem fortemente.

A cobertura do solo, proporcionada pelos resíduos culturais deixados na superfície, tem ação direta e efetiva na redução da erosão hídrica, pois promove a dissipação da energia cinética das gotas da chuva, diminuindo a desagregação das partículas de solo e o selamento superficial, e aumenta a infiltração de água. Atua, ain- 
da, na redução da velocidade do escoamento superficial e, conseqüentemente, no potencial erosivo da enxurrada (Sloneker \& Moldenhauer, 1977; Cogo et al., 1984; Zhou et al., 2002). A porcentagem de cobertura do solo proporcionada pelo resto de culturas é fundamental na redução das perdas de solo por erosão hídrica (Sloneker \& Moldenhauer, 1977), observando-se boa eficácia já com 30\% de cobertura (Lopes et al., 1987). No entanto, a persistência dessa proteção na superfície do solo irá depender do grau de incorporação dos resíduos culturais, bem como do método de preparo (Cogo et al., 2003).

Os métodos de preparo do solo utilizados em áreas florestais no Brasil variam muito, mas podem ser sintetizados em dois grandes grupos: o amplo revolvimento das camadas superficiais do solo - preparo convencional com aração e gradagem - e o cultivo mínimo, com preparo de solo restrito às linhas de plantio, mantendo os resíduos culturais sobre o terreno. Este último temse destacado no setor florestal nos últimos anos por garantir melhor conservação do solo e de suas propriedades (Gonçalves et al., 2002; Martins et al., 2003; Brito, 2004; Pires, 2004; Martins, 2005).

A expansão de uso das técnicas de cultivo mínimo no manejo de florestas plantadas reflete a preocupação atual do setor em se obter produtos florestais com boa qualidade, produtividade e rentabilidade, sem prejudicar a qualidade do solo em relação aos atributos relacionados à suscetibilidade à erosão hídrica e ao meio ambiente (Gonçalves \& Mello, 2000).

O preparo do solo pode também incluir a queima de resíduos vegetais, como prática de limpeza da área. Entre as conseqüências desta prática, a redução ou eliminação da cobertura vegetal favorece o escoamento superficial da água da chuva, agravando o processo erosivo (Santos et al., 1992). Outros efeitos negativos das queimadas sobre atributos do solo e ambiente têm desestimulado sua adoção, o que constitui um avanço da silvicultura brasileira nos últimos anos.

No Brasil, trabalhos sobre as perdas de solo e água por erosão hídrica em áreas de plantios florestais têm sido conduzidos. Entre esses trabalhos, destaca-se o de Ranzini \& Lima (2002), que verificaram que as perdas de um Podzólico Vermelho-Amarelo, em microbacias reflorestadas com eucalipto, variaram entre 0,03 e $0,08 \mathrm{Mg} \mathrm{ha}^{-1}$, sendo consideradas baixas quando comparadas com as perdas de solo de uma mata nativa e com o limite de tolerância estabelecido. Vital et al. (1999) observaram que, apesar de os valores de perdas de um Podzólico Vermelho-Amarelo terem praticamente dobrado no primeiro ano depois do corte raso de eucalipto em uma microbacia, os valores de $0,04 \mathrm{Mg} \mathrm{ha}^{-1}$ por ano são ainda significativamente menores do que os decorrentes do uso mais intensivo do solo.

Na região dos Tabuleiros Costeiros do Espírito Santo, Martins et al. (2003), comparando três classes de solo sob cultivo de eucalipto, observaram que as perdas de solo variaram entre 0,21 e 3,20 $\mathrm{Mg} \mathrm{ha}^{-1}$ por ano. Estes valores, apesar de ligeiramente superiores aos obtidos na mata nativa, são bastante inferiores aos do solo descoberto, e estão muito abaixo do limite de tolerância médio estabelecido (11,33 $\mathrm{Mg} \mathrm{ha}^{-1}$ por ano). Em área de Areia Quartzosa, cultivada com Eucalyptus grandis, Lima (1996) observou redução dos valores de perda de solo do primeiro para o quarto ano. Os valores obtidos no início variavam entre 1,0 e 6,5 $\mathrm{Mg} \mathrm{ha}^{-1}$ por ano, decrescendo para 0,01 a $0,14 \mathrm{Mg} \mathrm{ha}^{-1}$ por ano no quarto ano, enquanto na parcela sem cobertura vegetal, as perdas de solo variaram entre 3,2 e 11,32 $\mathrm{Mg} \mathrm{ha}^{-1}$ por ano. Tais avaliações são relevantes no monitoramento e previsão da sustentabilidade dos sistemas de uso e manejo aos quais o solo está sendo submetido.

Ao estudar os efeitos do desmatamento da caatinga sobre as perdas de solo e água, no município de Sumé, $\mathrm{PB}$, Albuquerque et al. (2001) observaram que a interceptação das gotas de chuvas pelo dossel da mata e a existência de uma rica serrapilheira são essenciais na redução da erosão hídrica.

No Estado de Minas Gerais, região do Vale do Rio Doce, Município de Guanhães, Brito (2004), trabalhando em área de Latossolo Vermelho muito argiloso em relevo ondulado, sob cultivo de eucalipto, concluiu que a queima de resíduos vegetais e a orientação de plantio não promoveram efeito significativo sobre os resultados de perdas por erosão hídrica. Todos os sistemas com eucalipto apresentaram valores muito baixos de perdas de solo, em relação ao limite de tolerância estabelecido e valores bastante próximos aos da floresta nativa, evidenciando adequação do sistema de manejo e sustentabilidade desses ambientes quanto à erosão hídrica.

O objetivo deste trabalho foi avaliar as perdas de solo e água por erosão hídrica, sob chuva natural, em diferentes sistemas de manejo de florestas de eucalipto, em relação à mata nativa, pastagem e solo descoberto, em um Latossolo Vermelho-Amarelo. 


\section{Material e Métodos}

O experimento foi conduzido na estação experimental da empresa Celulose Nipo Brasileira S.A. (Cenibra S.A.), localizada no Município de Belo Oriente, situada na Bacia hidrográfica do Rio Doce, região centro-leste do Estado de Minas Gerais. O clima predominante nessa região é do tipo tropical, com inverno seco e estação chuvosa no verão (Aw, segundo a classificação de Köppen), apresentando temperatura média variando entre 22 e $27^{\circ} \mathrm{C}$ por ano, com umidade relativa do ar de $67 \%$, precipitações médias anuais variando de 701 a $1.500 \mathrm{~mm}$ e altitude média de 240 m (Cenibra, 2001).

O solo foi classificado como Latossolo VermelhoAmarelo (LVA) distrófico típico, textura muito argilosa, relevo ondulado (Cenibra, 2001). A tolerância de perdas de solo por erosão hídrica admissível para esta classe de solo na região é de 7,17 t ha-1 por ano (Pires, 2004).

Os tratamentos constituíram-se de três sistemas de manejo do eucalipto: plantado em nível; plantado na direção do declive; plantado na direção do declive com queima de restos culturais; dois sistemas caracterizando situações de uso do solo na região, pastagem plantada de Brachiaria sp. e solo descoberto e um sistema utilizado como referencial, representando a condição de mata nativa. Os sistemas plantado em nível, plantado na direção do declive, plantado na direção do declive com queima de restos culturais e solo descoberto foram instalados em áreas que apresentavam o mesmo histórico de uso. As declividades do solo nos sistemas sob eucalipto foram 34,4, 30,6 e 36,4\%, no plantado em nível, plantado na direção do declive, plantado na direção do declive com queima dos restos culturais, respectivamente; na pastagem plantada foi de $24,9 \%$, no solo descoberto foi de $32,5 \%$ e na mata nativa foi de $42,4 \%$.

O primeiro plantio de eucalipto foi realizado em 1978, seguido de mais três ciclos de plantio. O estudo foi implantado no quarto plantio que foi realizado em 6 de maio de 2002, quando foi implantado o clone híbrido de Eucalyptus spp. com espaçamento de 3,0x3,3 m (mil árvores por hectare), em covas feitas manualmente com enxadão (cultivo mínimo), com as dimensões de 0,30x0,30x0,30 m. Antes do plantio, em abril de 2002, foi realizada uma aplicação de herbicida dessecante para controle de plantas daninhas e brotações. Depois do plantio foram feitas duas capinas manuais, em novembro de 2002 e em fevereiro de 2003. Na adubação de plantio, foram utilizados $90 \mathrm{~g}$ de NPK 6-30-6, $400 \mathrm{~g}$ de fosfato reativo e $1 \mathrm{~kg}$ de calcário por cova, e $300 \mathrm{~g}$ de $\mathrm{KCl}$ por planta, aplicados em cobertura.
As parcelas para avaliação das perdas de solo e água foram instaladas no campo, com dimensões de $14 \times 24 \mathrm{~m}$ para os sistemas eucalipto plantado em nível; plantado na direção do declive; plantado na direção do declive com queima de restos culturais e 4x24 m para os sistemas pastagem plantada, solo descoberto e mata nativa (Figura 1). Essas parcelas foram contornadas com chapas galvanizadas com $40 \mathrm{~cm}$ de altura, enterradas a uma profundidade de $20 \mathrm{~cm}$. O comprimento da parcela acompanha o sentido do declive do terreno. Na parte inferior das parcelas foram colocadas calhas coletoras, nas quais saíam canos de plástico de três polegadas para conduzir a enxurrada até os tanques coletores. O sistema coletor era composto de um tanque de sedimentação com capacidade de $500 \mathrm{~L}$ e um tanque coletor de água e sedimentos com capacidade para $250 \mathrm{~L}$ (Figura 1). Entre o tanque de sedimentação e o tanque coletor havia um sistema divisor do tipo Geib com 15 janelas para que, depois do enchimento do tanque de sedimentação, apenas $1 / 15$ da enxurrada fosse conduzido para o tanque coletor.

As coletas para determinação das perdas de solo e água foram realizadas a cada evento de chuva considerada erosiva, no período compreendido entre outubro de 2002 e fevereiro de 2004. Chuvas cujos registros foram maiores que $10 \mathrm{~mm}$, com intensidade máxima maior que

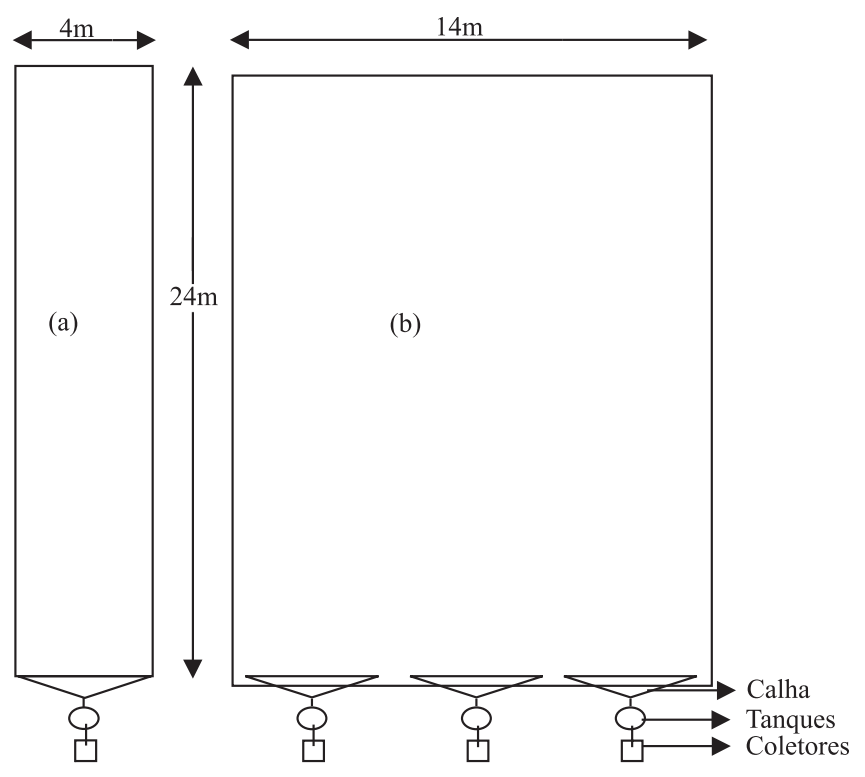

Figura 1. Desenho esquemático das parcelas de coleta de água e sedimentos. Parcelas (a) foram instaladas nos sistemas mata nativa, pastagem plantada e solo descoberto, e parcelas (b) nos sistemas com eucalipto. 
$24 \mathrm{~mm} \mathrm{~h}^{-1}$, em 15 minutos, ou energia cinética maior que 3,6 MJ, foram consideradas erosivas (Maria, 1994). A fim de quantificar as perdas de solo e água, amostras de enxurrada e sedimentos foram retiradas dos tanques de coleta. Depois de agitar as amotras, foram retiradas três alíquotas de volume predeterminado, as quais foram transferidas para o laboratório e submetidas à decantação. O material decantado foi secado em estufa a $105^{\circ} \mathrm{C}$. Os cálculos das perdas de solo foram efetuados em termos de $\mathrm{t} \mathrm{ha}^{-1}$ e das perdas de água em $\mathrm{mm}$. O potencial de arraste de sedimentos do solo (PAS) foi calculado dividindo-se as perdas de solo em $\mathrm{t} \mathrm{ha}{ }^{-1}$ pelas perdas de água em mm (Martins, 2001). Os estudos de perdas de solo e água em parcelas-padrão não apresentam repetições de tratamentos.

A amostragem para determinação de atributos físicos e carbono orgânico total do solo (Tabela 1) foi efetuada em outubro de 2002. Em amostras com estrutura indeformada coletadas com amostrador de Uhland em cilindros com volume médio de $313,5 \mathrm{~cm}^{3}$, na profundidade de $10 \mathrm{~cm}$, foram determinados: densidade do solo (Blake \& Hartge, 1986), volume total de poros (Danielson \& Sutherland, 1986), macroporosidade e microporosidade (Embrapa, 1997).

Amostras com estrutura deformada foram coletadas na profundidade de $0-20 \mathrm{~cm}$, em quatro repetições, sendo secadas ao ar e passadas na peneira de $2 \mathrm{~mm}$ (terra fina) para análise do índice de floculação (IF) de acordo com Embrapa (1997). O carbono orgânico total (CO) foi determinado segundo Embrapa (1997).
Agregados secados ao ar durante 24 horas foram padronizados quanto ao tamanho, em peneiras entre 7,93 a $4,76 \mathrm{~mm}$. A estabilidade de agregados foi determinada por meio de peneiramento em água, depois do préumedecimento lento dos agregados por capilaridade durante 24 horas (Oliveira et al., 1983; Kemper \& Rosenau, 1986) e agregados sem pré-umedecimento, utilizando as peneiras de 2,00, 1,00, 0,50, 0,25 e 0,105 mm. Os resultados foram expressos em diâmetro médio geométrico (DMG) dos agregados de acordo com Kemper \& Rosenau (1986).

O teste de resistência do solo à penetração foi realizado em campo, na profundidade de $60 \mathrm{~cm}$, utilizandose o penetrômetro de impacto modelo IAA/Planalsucar - Stolf (Stolf et al., 1983), com dez repetições para cada sistema de manejo estudado. A umidade atual do solo foi determinada segundo Embrapa (1997) para as profundidades de 0-20 cm, 20-40 cm e 40-60 cm.

$\mathrm{Na}$ análise estatística dos atributos físicos e do carbono orgânico total, adotou-se o delineamento experimental inteiramente casualizado. As análises estatísticas (análise de variância e teste de médias) foram realizadas com o auxílio do programa SISVAR. A comparação entre as médias nos sistemas de manejo de coleta foi realizada pelo teste de Scott-Knott (Scott \& Knott, 1974) a 5\% de probabilidade. Foram feitas análises de correlação de Pearson entre as perdas totais de solo com seus atributos físicos e químicos, verificando-se a significância dos coeficientes de correlação pelo teste t de Student.

Tabela 1. Densidade do solo (Ds); volume total de poros (VTP); macropororosidade (MACRO), microporosidade (MICRO); índice de floculação (IF); diâmetro médio geométrico dos agregados com pré-umedecimento (DMGcu); diâmetro médio geométrico dos agregados sem pré-umedecimento (DMGsu); porcentagem dos agregados maior que 2 mm, com pré-umedecimento (Acu >2 mm); porcentagem dos agregados maior que $2 \mathrm{~mm}$, sem pré-umedecimento (Asu >2 mm) e carbono orgânico total (CO) de Latossolo Vermelho-Amarelo distrófico típico, textura muito argilosa, sob diferentes sistemas de manejo ${ }^{(1)}$.

\begin{tabular}{|c|c|c|c|c|c|c|}
\hline \multirow[t]{2}{*}{ Atributos } & \multicolumn{6}{|c|}{ Sistemas } \\
\hline & $\mathrm{MN}$ & $\mathrm{PP}$ & EN & $\mathrm{EC}$ & ECQ & SD \\
\hline Ds $\left(\mathrm{kg} \mathrm{dm}^{-3}\right)$ & $0,93 b$ & $1,20 \mathrm{a}$ & $1,13 a$ & $1,21 \mathrm{a}$ & $1,19 \mathrm{a}$ & $1,29 \mathrm{a}$ \\
\hline $\operatorname{VTP}\left(\mathrm{m}^{3} \mathrm{~m}^{-3}\right)$ & $0,60 \mathrm{a}$ & $0,50 \mathrm{~b}$ & $0,55 \mathrm{a}$ & $0,51 b$ & $0,52 b$ & $0,47 b$ \\
\hline $\operatorname{MACRO}\left(\mathrm{m}^{3} \mathrm{~m}^{-3}\right)$ & $0,30 \mathrm{a}$ & $0,15 \mathrm{c}$ & $0,26 \mathrm{a}$ & $0,19 b$ & $0,21 b$ & $0,09 \mathrm{c}$ \\
\hline $\operatorname{MICRO}\left(\mathrm{m}^{3} \mathrm{~m}^{-3}\right)$ & $0,30 \mathrm{c}$ & $0,35 b$ & $0,29 \mathrm{c}$ & $0,32 \mathrm{c}$ & $0,30 \mathrm{c}$ & $0,38 \mathrm{a}$ \\
\hline IF $(\%)$ & $69 \mathrm{~d}$ & $81 \mathrm{c}$ & $75 d$ & $78 \mathrm{~d}$ & $84 c$ & $99 a$ \\
\hline DMGcu (mm) & $4,55 \mathrm{a}$ & $4,36 \mathrm{a}$ & $4,57 \mathrm{a}$ & $4,46 \mathrm{a}$ & $4,35 \mathrm{a}$ & $1,95 \mathrm{~b}$ \\
\hline DMGsu (mm) & $4,22 \mathrm{a}$ & $3,05 \mathrm{a}$ & $3,36 \mathrm{a}$ & $3,32 \mathrm{a}$ & $2,53 \mathrm{a}$ & $0,81 b$ \\
\hline Acu $>2 \mathrm{~mm}(\%)$ & $95,90 \mathrm{a}$ & $93,91 \mathrm{a}$ & $96,16 a$ & $94,52 \mathrm{a}$ & $93,81 \mathrm{a}$ & $56,06 \mathrm{~b}$ \\
\hline Asu $>2$ mm (\%) & $92,33 a$ & $76,24 a$ & $80,12 \mathrm{a}$ & $76,69 a$ & $64,21 \mathrm{a}$ & $22,73 b$ \\
\hline $\mathrm{CO}\left(\mathrm{g} \mathrm{kg}^{-1}\right)$ & $37,2 \mathrm{a}$ & $22,0 \mathrm{~b}$ & $33,9 a$ & $27,6 \mathrm{a}$ & $36,6 a$ & $8,1 \mathrm{c}$ \\
\hline
\end{tabular}

${ }^{(1)} \mathrm{MN}$ : mata nativa; PP: pastagem plantada; EN: eucalipto plantado em nível; EC: eucalipto plantado na direção do declive; ECQ: eucalipto plantado na direção do declive com queima dos restos culturais; SD: solo descoberto; médias seguidas pela mesma letra na linha não diferem entre si pelo teste de Scott-Knott a 5\% de probabilidade. 


\section{Resultados e Discussão}

A precipitação total no período de estudo foi de 2.009,4 mm, sendo 575,8 mm no ano de 2.002, $894 \mathrm{~mm}$ no ano de 2003 e 539,8 mm no ano de 2004, concentrando-se no período de outubro a fevereiro (Figura 2).

Os picos da perda de solo coincidiram com os meses de maior precipitação (Tabela 2), o que pode ser expli-

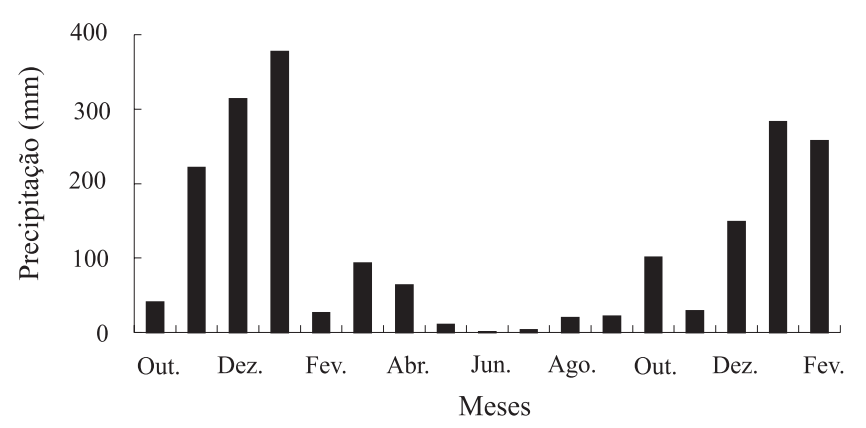

Figura 2. Precipitação pluvial mensal (mm) do período de outubro de 2002 a fevereiro de 2004. cado pela alteração, no decorrer da chuva, das condições da superfície e da umidade do solo; quando ocorre o pico de maior intensidade, o solo está muito úmido, favorecendo a desagregação e o transporte das partículas de solo.

As perdas de solo (Tabela 2) apresentaram variação de 0,0 a 3,46 $\mathrm{Mg} \mathrm{ha}^{-1}$ por ano. As menores perdas acumuladas foram observadas para o sistema de mata nativa, mesmo sendo este o sistema de maior declividade (42,4\%). A interceptação das gotas de chuvas pelo dossel da mata, a existência de uma rica serrapilheira e os maiores teores de carbono orgânico total (Tabela 1), formando agregados mais estáveis, ajudam a explicar tais resultados. Observações semelhantes foram feitas por Albuquerque et al. (2001), Martins et al. (2002, 2003), Brito (2004) e Martins (2005).

Entre os sistemas de manejo com floresta de eucalipto, observa-se que o eucalipto plantado em nível apresentou valores relativamente próximos de perda de solo em relação à mata nativa, indicando, assim, a maior sustentabilidade desse sistema. $\mathrm{O}$ eucalipto plantado na

Tabela 2. Valores de perdas de solo ( $\mathrm{t} \mathrm{ha} \mathrm{P}^{-1}$ por ano) por erosão hídrica para cada sistema de manejo, durante o período de outubro de 2002 a fevereiro de $2004^{(1)}$.

\begin{tabular}{|c|c|c|c|c|c|c|}
\hline Meses & $\mathrm{MN}$ & $\mathrm{PP}$ & EN & $\mathrm{EC}$ & ECQ & SD \\
\hline \multicolumn{7}{|c|}{2002} \\
\hline Outubro & 0,000 & 0,086 & 0,002 & 0,005 & 0,014 & 0,009 \\
\hline Novembro & 0,006 & 0,012 & 0,005 & 0,006 & 0,012 & 3,462 \\
\hline Dezembro & 0,006 & 0,007 & 0,004 & 0,003 & 0,005 & 0,818 \\
\hline Total do período & 0,012 & 0,104 & 0,011 & 0,014 & 0,032 & 4,289 \\
\hline \multicolumn{7}{|c|}{2003} \\
\hline Janeiro & 0,078 & 0,095 & 0,018 & 0,071 & 0,433 & 2,891 \\
\hline Fevereiro & 0,001 & 0,000 & 0,000 & 0,001 & 0,002 & 0,001 \\
\hline Março & 0,000 & 0,000 & 0,001 & 0,005 & 0,044 & 0,103 \\
\hline Abril & 0,022 & 0,000 & 0,006 & 0,006 & 0,046 & 0,384 \\
\hline Maio & 0,000 & 0,000 & 0,000 & 0,000 & 0,000 & 0,000 \\
\hline Junho & 0,000 & 0,000 & 0,000 & 0,000 & 0,004 & 0,031 \\
\hline Julho & 0,000 & 0,000 & 0,000 & 0,000 & 0,000 & 0,000 \\
\hline Agosto & 0,000 & 0,000 & 0,000 & 0,000 & 0,004 & 0,031 \\
\hline Setembro & 0,000 & 0,000 & 0,000 & 0,000 & 0,000 & 0,000 \\
\hline Outubro & 0,002 & 0,002 & 0,004 & 0,004 & 0,013 & 0,192 \\
\hline Novembro & 0,002 & 0,000 & 0,003 & 0,003 & 0,018 & 0,214 \\
\hline Dezembro & 0,002 & 0,001 & 0,008 & 0,111 & 0,023 & 1,048 \\
\hline Total do período & 0,109 & 0,100 & 0,041 & 0,201 & 0,587 & 4,895 \\
\hline \multicolumn{7}{|c|}{2004} \\
\hline Janeiro & 0,013 & 0,003 & 0,161 & 0,151 & 0,161 & 2,975 \\
\hline Fevereiro & 0,004 & 0,003 & 0,048 & 0,020 & 0,036 & 1,019 \\
\hline Total do período & 0,016 & 0,005 & 0,208 & 0,171 & 0,196 & 3,995 \\
\hline Total acumulado & 0,137 & 0,209 & 0,260 & 0,386 & 0,815 & 13,179 \\
\hline
\end{tabular}

${ }^{(1)} \mathrm{MN}$ : mata nativa; PP: pastagem plantada; EN: eucalipto plantado em nível; EC: eucalipto plantado na direção do declive; ECQ: eucalipto plantado na direção do declive com queima dos restos culturais; SD: solo descoberto. 
direção do declive com queima dos restos culturais foi o que apresentou a maior diferença em relação à mata nativa, o que confirma o efeito negativo do fogo no solo (Santos et al., 1992; Gonçalves \& Stape, 2002).

Comparando as perdas de solo com a tolerância admissível $\left(7,17 \mathrm{t} \mathrm{ha}^{-1}\right.$ por ano) determinada por Pires (2004) para este solo, observa-se que todos os sistemas de manejo apresentaram valores muito inferiores.

Os sistemas mata nativa e pastagem plantada foram os que apresentaram os menores valores de perda de água (Tabela 2), seguindo a mesma tendência das perdas de solo. Isto se deve às variações da cobertura, à incorporação ao sistema de distintas quantidades e tipos de material vegetal da parte aérea e raízes, e à resistência de resíduos vegetais à decomposição e ao transporte pela enxurrada (Foster, 1982).

Entre os sistemas de manejo florestal, houve variações nas perdas de água (Tabela 3), independentemente das classes de declividade, concordando com trabalhos de Schick et al. (2000) e Cogo et al. (2003). Os maiores valores de perdas de água, observados nos sistemas de manejo da cultura do eucalipto, em relação à mata nativa e à pastagem plantada, estão relacionados à exposição do solo por ocasião da implantação dos sistemas. Somente depois de um ano de implantação é que esses sistemas formam sub-bosques e, assim, tende a decrescer a perda de água, igualando-se à da mata nativa (Lima, 1996; Vital et al., 1999).

Os resultados obtidos para as perdas de água entre os sistemas florestais com eucalipto obedecem à seqüência eucalipto plantado na direção do declive $<$ eucalipto plantado em nível < eucalipto plantado na direção do declive com queima dos restos culturais. Esses resultados evidenciam a maior eficiência na redução das perdas de água por enxurrada dos sistemas eucalipto plantado na direção do declive e eucalipto plantado em nível, porém, deve-se ressaltar que esse tipo de estudo exige tempo maior para sua validação. Os maiores valores observados no eucalipto plantado na direção do declive com queima dos restos culturais mostram que o fogo aumenta a repelência à água (Gonçalves \& Stape, 2002) e diminui a taxa de infiltração de água no solo.

Com exceção do solo descoberto, os outros sistemas praticamente não apresentaram variação de potencial

Tabela 3. Valores de perdas de água (mm por mês) por erosão hídrica para cada sistema de manejo, durante o período de outubro de 2002 a fevereiro de $2004^{(1)}$.

\begin{tabular}{|c|c|c|c|c|c|c|}
\hline Meses & $\mathrm{MN}$ & $\mathrm{PP}$ & EN & $\mathrm{EC}$ & ECQ & SD \\
\hline & \multicolumn{6}{|c|}{2002} \\
\hline Outubro & 0,000 & 1,659 & 0,485 & 1,456 & 1,244 & 0,195 \\
\hline Novembro & 1,873 & 2,775 & 6,573 & 5,636 & 7,421 & 9,045 \\
\hline Dezembro & 1,873 & 0,624 & 3,769 & 3,116 & 4,648 & 6,703 \\
\hline Total do período & 3,746 & 5,058 & 10,827 & 3,746 & 13,311 & 15,943 \\
\hline & \multicolumn{6}{|c|}{2003} \\
\hline Janeiro & 7,856 & 14,372 & 29,003 & 31,219 & 34,173 & 16,724 \\
\hline Fevereio & 0,532 & 0,104 & 0,555 & 0,866 & 1,219 & 0,161 \\
\hline Março & 1,457 & 0,486 & 3,001 & 3,028 & 7,569 & 3,045 \\
\hline Abril & 0,518 & 0,532 & 1,235 & 1,344 & 4,053 & 3,523 \\
\hline Maio & 0,000 & 0,000 & 0,000 & 0,000 & 0,000 & 0,035 \\
\hline Junho & 0,155 & 0,017 & 0,363 & 0,397 & 0,535 & 0,035 \\
\hline Julho & 0,000 & 0,000 & 0,000 & 0,000 & 0,000 & 0,035 \\
\hline Agosto & 0,173 & 0,161 & 0,566 & 0,472 & 0,968 & 1,316 \\
\hline Setembro & 0,063 & 0,063 & 0,109 & 0,161 & 0,190 & 0,035 \\
\hline Outubro & 0,982 & 1,051 & 3,294 & 3,091 & 5,053 & 5,370 \\
\hline Novembro & 0,641 & 0,699 & 2,068 & 2,149 & 3,190 & 4,130 \\
\hline Dezembro & 2,399 & 1,532 & 5,907 & 5,212 & 6,855 & 9,294 \\
\hline \multirow[t]{2}{*}{ Total do período } & 14,778 & 19,017 & 46,101 & 47,940 & 63,805 & 43,701 \\
\hline & \multicolumn{6}{|c|}{2004} \\
\hline Janeiro & 3,399 & 2,151 & 11,979 & 11,881 & 18,322 & 14,405 \\
\hline Fevereiro & 2,637 & 1,943 & 8,892 & 8,952 & 11,715 & 11,563 \\
\hline Total do período & 6,036 & 4,094 & 20,871 & 6,036 & 30,037 & 25,968 \\
\hline Total acumulado & 24,554 & 28,169 & 77,802 & 57,722 & 107,152 & 85,610 \\
\hline
\end{tabular}

${ }^{(1)} \mathrm{MN}$ : mata nativa; PP: pastagem plantada; EN: eucalipto plantado em nível; EC: eucalipto plantado na direção do declive; ECQ: eucalipto plantado na direção do declive com queima dos restos culturais; SD: solo descoberto. 
de arraste de sedimentos (PAS), o que se deve principalmente à interceptação das gotas de chuva pela copa das árvores e à proteção feita pela serrapilheira nos sistemas florestais. O menor valor de PAS verificado no eucalipto em nível, em relação aos outros sistemas florestais, mostra sua boa eficiência quanto à conservação do solo (Figura 3). Na China, estudos semelhantes foram feitos por Zhou et al. (2002), em solo laterítico derivado de granito, onde foram encontrados valores para reflorestamento misto, eucalipto e solo descoberto, na ordem de $0,0003,0,0091$ e $0,0437 \mathrm{t} \mathrm{ha}^{-1} \mathrm{~mm}^{-1}$, respectivamente.

Entre os atributos do solo avaliados (Tabela 1), a densidade do solo apresentou diferença entre a mata nativa (menor valor) e os outros sistemas (valores mais altos); no tocante ao volume total de poros e macroporos, apenas o sistema eucalipto plantado em nível não diferiu da mata nativa, porém esses atributos não apresentaram correlação significativa com as perdas de solo (Tabela 4). Quanto ao atributo índice de floculação, apenas o eucalipto plantado na direção do declive com queima dos restos culturais apresentou diferença em relação à condição de mata nativa. Em relação aos microporos, diâmetro médio geométrico dos agregados, agregados $>2 \mathrm{~mm}$ e carbono orgânico total, não foram evidenciadas alterações entre os sistemas eucalipto plantado em nível, eucalipto plantado na direção do declive, eucalipto plantado na direção do declive com queima dos restos culturais e mata nativa. Os atributos DMG, agregados $>2 \mathrm{~mm}$ e CO apresentaram correlações negativas com as perdas de solo (Tabela 4), já o índice de

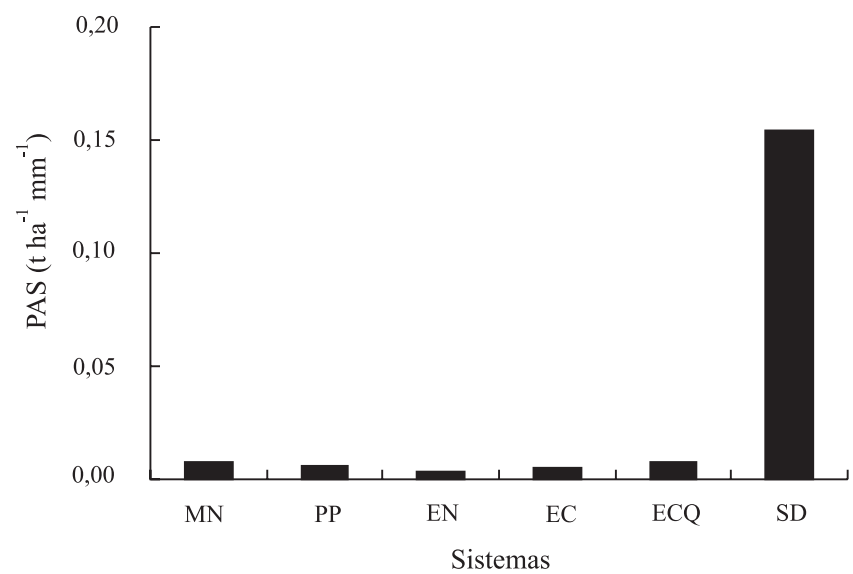

Figura 3. Potencial de arraste de sedimentos (PAS) para os sistemas mata nativa (MN); pastagem plantada (PP); eucalipto plantado em nível (EN); eucalipto plantado na direção do declive (EC); eucalipto plantado na direção do declive com queima de restos culturais (ECQ) e solo descoberto (SD), no período de outubro de 2002 a fevereiro de 2004. floculação apresentou correlação positiva. Resultados semelhantes foram observados por Cogo et al. (1984), Albuquerque et al. (2001), Martins (2001), Martins et al. (2002, 2003) e Brito (2004).

A umidade atual do solo no momento do teste de resistência do solo à penetração não apresentou diferenças significativas entre os sistemas estudados, sendo que os valores apresentaram uma amplitude de 0,20 a $0,27 \mathrm{~m}^{3} \mathrm{~m}^{-3}$, estando próximos da capacidade de campo do solo estudado.

Observa-se, de maneira geral, em todos os sistemas estudados, aumento dos valores de resistência do solo à penetração em relação à mata nativa, principalmente na camada compreendida entre as profundidades de 10 e $20 \mathrm{~cm}$, destacando-se que o valor máximo foi obtido no sistema eucalipto plantado na direção do declive, seguido do solo descoberto e do sistema eucalipto plantado na direção do declive com queima dos restos culturais (Figura 4). Esses maiores valores nos sistemas com eucalipto estão relacionados ao histórico de uso, incluindo operações de mecanização florestal por ocasião da colheita do ciclo anterior e do plantio no ciclo estudado (Silva et al., 2000). Valores altos de resistência do solo à penetração, na ordem de 5,0 MPa, são admitidos por Ehlers et al. (1983), em sistemas conservacionistas com maior aporte de carbono orgânico e presença de raízes crescendo por canais contínuos, deixados pela fauna do solo e pelo sistema radicular decomposto. O gradiente crescente de resistência do solo à penetração na camada de $20-40 \mathrm{~cm}$ para a mata nativa pode ser atribuído ao processo pedogenético conhecido como adensamento (Martins et al., 2002). No sistema de pastagem plantada, os valores elevados de resistência do solo à penetração na profundidade de $10-20 \mathrm{~cm}$ podem ser atribuídos

Tabela 4. Coeficientes de correlação entre perdas de solo por erosão hídrica e atributos de solo(1).

\begin{tabular}{lc}
\hline Atributos & Coeficiente de correlação com perdas de solo \\
\hline Ds $\left(\mathrm{kg} \mathrm{dm}^{-3}\right)$ & $0,28^{\mathrm{ns}}$ \\
$\operatorname{VTP}\left(\mathrm{m}^{3} \mathrm{~m}^{-3}\right)$ & $-0,11^{\mathrm{ns}}$ \\
MACRO $\left(\mathrm{m}^{3} \mathrm{~m}^{-3}\right)$ & $-0,24^{\mathrm{ns}}$ \\
MICRO $\left(\mathrm{m}^{-3} \mathrm{~m}^{-3}\right)$ & $0,43^{\mathrm{ns}}$ \\
IF $(\%)$ & $0,81^{*}$ \\
DMG $(\mathrm{mm})$ & $-0,95^{*}$ \\
$>2 \mathrm{~mm}(\mathrm{~mm})$ & $-0,97^{*}$ \\
RP & $0,42^{\mathrm{ns}}$ \\
CO $\left(\mathrm{g} \mathrm{kg} \mathrm{gga}^{-1}\right)$ & $-0,92^{*}$ \\
\hline
\end{tabular}

(1)Ds: densidade do solo; VTP: volume total de poros; MACRO: macroporosidade; MICRO: microporosidade; IF: índice de floculação; DMG: diâmetro médio geométrico dos agregados; $\mathrm{RP}_{0-5 \mathrm{~cm}}$ : resistência do solo à penetração na profundidade de $0-5$ cm, CO: carbono orgâni-

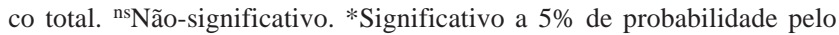
teste $\mathrm{t}$. 


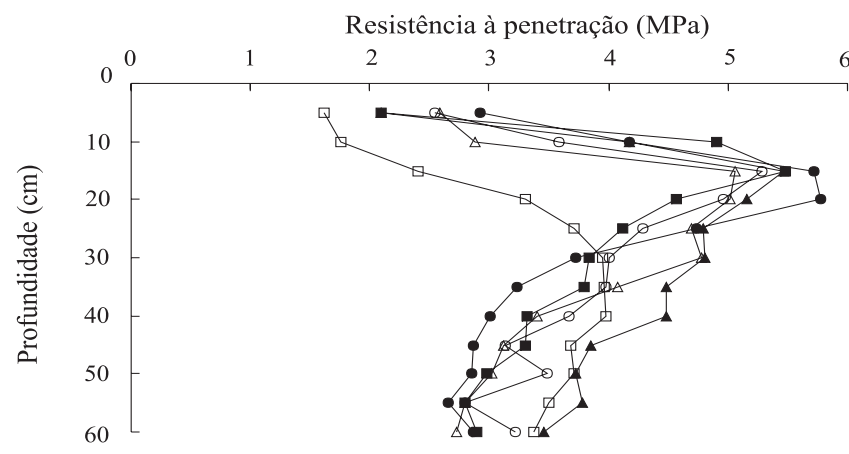

Figura 4. Resistência à penetração do Latossolo Vermelho Amarelo distrófico típico, textura muito argilosa, na profundidade de 0 a $60 \mathrm{~cm}$, sob os sistemas mata nativa ( $\square$ ); pastagem plantada $(\square)$; eucalipto plantado em nível $(\bigcirc)$; eucalipto plantado na direção do declive $(\bullet$ ); eucalipto plantado na direção do declive com queima de restos culturais $(\triangle)$ e solo descoberto $(\boldsymbol{\Delta})$.

ao efeito do pisoteio de animais, o que é atenuado em profundidades maiores.

\section{Conclusões}

1. Entre os sistemas florestais, o eucalipto em nível é o que mais se aproxima da mata nativa em termos de perdas de solo, indicando, assim, maior sustentabilidade desse sistema no que diz respeito à erosão hídrica.

2. Os maiores valores de perda de água são encontrados no sistema eucalipto plantado na direção do declive com queima de restos culturais.

3. Todos os sistemas de manejo do eucalipto estudados apresentaram perdas de solo muito inferiores ao valor limite de tolerância.

\section{Referências}

ALBUQUERQUE, A.W.; LOMBARDI NETO, F.; SRINIVASAN, V.S. Efeito do desmatamento da caatinga sobre as perdas de solo e água de um Luvissolo em Sumé (PB). Revista Brasileira de Ciência do Solo, v.25, p.121-128, 2001.

ALLMARAS, R.R.; BURWELL, R.E.; LARSON, W.E.; HOLT, R.F.; NELSON, W.W. Total porosity and random roughness of the interrow zone as influenced by tillage. Washington: Agricultural Research Service, US Department of Agriculture, 1966. 22p. (USDA. Conservation research report, 7).

BLAKE, G.R.; HARTGE, K.H. Bulk density. In: KLUTE, A. (Ed.). Methods of soil analysis. $2^{\text {nd }}$ ed. Madison: American Society of Agronomy, 1986. v.1, p.363-375.

BRITO, L.F. Erosão hídrica de Latossolo Vermelho distrófico típico em áreas de pós-plantio de eucalipto na região de
Guanhães (MG). 2004. 78p. Dissertação (Mestrado) - Universidade Federal de Lavras, Lavras.

CENIBRA. Levantamento semidetalhado dos solos das regiões do Rio Doce, Cocais, Sabinópolis e Virginópolis. Ipatinga, 2001. v.1, 101p.

COGO, N.P.; LEVIEN, R.; SCHWARZ, R.A. Perdas de solo e água por erosão hídrica influenciadas por métodos de preparo, classes de declive e níveis de fertilidade do solo. Revista Brasileira de Ciência do Solo, v.27, p.743-753, 2003.

COGO, N.P.; MOLDENHAUER, W.C.; FOSTER, G.R. Soil loss reductions from conservation tillage practices. Soil Science Society of America, v.48, p.368-373, 1984.

DANIELSON, R.E.; SUTHERLAND, P.L. Porosity. In: KLUTE, A. (Ed.). Methods of soil analysis: physical and mineralogical methods. Madison: American Society of Agronomy, 1986. p.443461.

EHLERS, W.; KOPKE, U.; HESSE, F.; BOHM, W. Penetration resistance and root growth of oats in tilled and untilled loess soil. Soil and Tillage Research, v.3, p.261-275, 1983.

EMBRAPA. Centro Nacional de Pesquisa de Solos (Rio de Janeiro, RJ). Manual de métodos de análises de solo. 2.ed. Rio de Janeiro, 1997. 212p.

FOSTER, G.R. Modeling the erosion process. In: HAAN, C.T.; JOHNSON, H.P.; BRAKENSIEK, D.L. (Ed.). Hydrologic modeling of small watersheds. St. Joseph: American Society of Agricultural Engineers, 1982. p.297-380. (ASAE monograph, 5).

GONÇALVES, J.L. de M.; MELLO, S.L.M. O sistema radicular das árvores. In: GONÇALVES, J.L. de M.; BENEDETTI, V. (Ed.). Nutrição e fertilização florestal. Piracicaba: Ipef, 2000. p.219267.

GONÇALVES, J.L. de M.; STAPE, J.L. Conservação e cultivo de solos para plantações florestais. Piracicaba: Ipef, 2002. 498p.

KEMPER, W.D.; ROSENAU, R.C. Aggregate stability and size distribution. In: KLUTE, A. Methods of soil analysis: physical and mineralogical methods. $2^{\text {nd }}$ ed. 1986. v.1, p.425-441. (Agronomy monograph, 9).

LIMA, W.P. Impacto ambiental do eucalipto. 2.ed. São Paulo: Universidade de São Paulo, 1996. 301p.

LOPES, P.R.; COGO, N.P.; LEVIEN, R. Eficácia relativa de tipo e quantidade de resíduos culturais espalhados uniformemente sobre o solo na redução da erosão hídrica. Revista Brasileira de Ciência do Solo, v.11, p.71-75, 1987.

MARIA, I.C. de. Cálculo da erosividade da chuva. In: LOMBARDI NETO, F.; CASTRO, O.M. de; DECHEN, S.C.F.; VIEIRA, S.R.; MARIA, I.C. de. Manual de programas de processamento de dados de campo e de laboratório para fins de experimentação em conservação do solo. Campinas: Instituto Agronômico, 1994. Não paginado.

MARTINS, S.G. Erosão hídrica em povoamento de eucalipto sobre solos coesos nos Tabuleiros Costeiros, ES. 2005. 106p. Tese (Doutorado) - Universidade Federal de Lavras, Lavras.

MARTINS, S.G. Erosão hídrica em sistemas florestais, nos Tabuleiros Costeiros da região de Aracruz - ES: primeira 
aproximação. 2001. 59p. Dissertação (Mestrado) - Universidade Federal de Lavras, Lavras.

MARTINS, S.G.; SILVA, M.L.N.; CURI, N.; FERREIRA, M.M. Avaliação de atributos físicos de um Latossolo Vermelho distroférrico sob diferentes povoamentos florestais. Cerne, v.8, p.32-41, 2002.

MARTINS, S.G.; SILVA, M.L.N.; CURI, N.; FERREIRA, M.M.; FONSECA, S.; MARQUES, J.J.G.S.M. Perdas de solo e água por erosão hídrica em sistemas florestais na região de Aracruz (ES). Revista Brasileira de Ciência do Solo, v.27, p.395-403, 2003.

OLIVEIRA, M.; CURI, N.; FREIRE, J.C. Influência do cultivo na agregação de um Podzólico Vermelho-Amarelo textura média/argilosa da região de Lavras (MG). Revista Brasileira de Ciência do Solo, v.7, p.317-322, 1983.

PIRES, L.S. Sistemas de manejo de eucalipto e erosão hídrica em Latossolo Vermelho-Amarelo muito argiloso na região de Belo Oriente (MG). 2004. 84p. Dissertação (Mestrado) Universidade Federal de Lavras, Lavras.

RANZINI, M.; LIMA, W.P. Comportamento hidrológico, balanço de nutrientes e perdas de solo em duas microbacias reflorestadas com Eucalyptus, no Vale do Paraíba, SP. Scientia Forestalis, v.61, p.144-159, 2002.

SANTOS, D.; BAHIA, V.G.; TEIXEIRA, W.G. Queimadas e erosão do solo. Informe Agropecuário, v.16, p.62-68, 1992.

SCHICK, J.; BERTOL, I.; BATISTELA, O.; BALBINOT JÚNIOR, A.A. Erosão hídrica em Cambissolo Húmico Alumínico submetido a diferentes sistemas de preparo e cultivo do solo. I. Perdas de solo e água. Revista Brasileira de Ciência do Solo, v.24, p.427-436, 2000.

SCOTT, A.J.; KNOTT, M. Accouter analysis methods for grouping means in the analysis of variants. Biometrics, v.30, p.507-512, 1974.

SILVA, V.R. da; REINERT, D.J.; REICHERT, J.M. Susceptibilidade à compactação de um Latossolo Vermelho-Escuro e de um Podzólico Vermelho-Amarelo. Revista Brasileira de Ciência do Solo, v.24, p.239-249, 2000.

SLONEKER, L.L.; MOLDENHAUER, W.C. Measuring amounts of crop residue remaining after tillage. Journal of Soil and Water Conservation, v.32, p.231-236, 1977.

STOLF, R.; FERNANDES, J.; FURLANI NETO, V.L. Recomendação para o uso do penetrômetro de impacto modelo IAA/Planalsucar - Stolf. Piracicaba: IAA/Planalsucar, 1983. 9p. (Série penetrômetro de impacto. Boletim, 1).

VITAL, A.R.T.; LIMA, W.P.; POGGIANI, F.; CAMARGO, F.R.A. Biogeoquímica de uma microbacia após o corte raso de uma plantação de eucalipto de 7 anos de idade. Scientia Forestalis, v.55, p.17-28, 1999.

ZHOU, G.Y.; MORRIS, J.D.; YAN, J.H.; YU, Z.Y.; PENG, S.L. Hydrological impacts of refforestation with eucalypts and indigenous species: a case study in Southern China. Forest Ecology and Management, v.167, p.209-222, 2002. 